\title{
Internal Fixation of Gunshot Induced Fractures in Civilians: Anatomic and Functional Results of a Standard Protocol at an Urban Trauma Center
}

\author{
Anani Abalo*, Atsi Walla, Gamal Ayouba, Yaovi Yannick Dellanh, Kosivi Fortey, Assang Dossim \\ Department of Orthopaedics Tokoin Teaching Hospital, Lomé, Togo \\ Email: ‘abalgreg@yahoo.fr
}

Received 14 February 2016; accepted 22 March 2016; published 25 March 2016

Copyright @ 2016 by authors and Scientific Research Publishing Inc.

This work is licensed under the Creative Commons Attribution International License (CC BY). http://creativecommons.org/licenses/by/4.0/

(c) () Open Access

\begin{abstract}
Introduction: Despite extensive experience with civilian gunshot fractures or wounds, no consensus exists on a standard protocol to manage these injuries. Many authors recommended immediate debridement, but the optimal timing of internal fixation and the use of antibiotic have not been determined. The purpose of this paper is to present and discuss our experience. Material and methods: In January 2007, a treatment protocol was put in place for the evaluation and management of fractured extremities resulting from civilian gunshot wounds. Sixty-three patients with 64 fractures had been managed by this protocol for gunshot fractures between January 2005 and January 2012. There were 56 male and seven female. Their mean age was 33.1 years (range: 17 - 61 years). Thirteen patients $(20.6 \%)$ were able to provide a description of the weapon. Only 15 patients had entry and exit wounds. The mean follow-up period was 27 (range, 20 - 58) months. The main factors assessed were the surgical site infection, the fracture union and the functional status. Results: Out of the 63 patients, 14 patients developed a wound infection (five superficial and seven deep infections). Wound infection was significantly associated with associated injuries $(p=0.0388)$, fractures sites requiring fixation $(p=0.024)$, the fracture pattern $(p=0.0412)$, operative modalities ( $p$ $=0.0400)$. There were nine cases $(14.1 \%)$ of fracture non-union. The mean time to union was 15 weeks (range: 5 - 32 weeks). Five patients developed chronics osteomyelitis. The average SMFA score for all of the patients was 23.8 (range: 0 - 56.3). The mean dysfunctional and bother indexes were 18.3 (range: 0 - 52.7) and 22.6 (range: 0 - 66.1), respectively. The SMFA total score and dysfunction index had a significant correlation based on presence or absence of associated injuries ( $p$ $<0.0001)$. But bother index did not show the same correlation $(p=0.452)$. The average length of hospital stay was 11.3 days (range: 3 - 64). Conclusion: In civilian's gunshot induced fractures, internal fixation can be made according to standard protocol, with acceptable result.
\end{abstract}

*Corresponding author.

How to cite this paper: Abalo, A., Walla, A., Ayouba, G., Dellanh, Y.Y., Fortey, K. and Dossim, A. (2016) Internal Fixation of Gunshot Induced Fractures in Civilians: Anatomic and Functional Results of a Standard Protocol at an Urban Trauma Center. Open Journal of Orthopedics, 6, 63-70. http://dx.doi.org/10.4236/ojo.2016.63010 
Keywords

Fracture, Gunshot Fracture, Internal Fixation, Wound Infection, Surgical Treatment

\section{Introduction}

The increase in the number of firearms has led to an increase in gunshot wounds in civilians [1] [2]. Many such injuries result in a fractured extremity that requires orthopaedic management. Despite extensive experience with civilian gunshot fractures or wounds, no consensus exists on a standard protocol to manage these injuries [2]-[7].

All recommended early debridement, but the optimal timing of internal fixation and the use of antibiotic have not been determined. Most published investigations on the subject have treated these injuries with stabilisation on a delayed basis, 7 to 10 days after injury, when the risk of infection was believed to be decreased [8]-[11]. Some authors have demonstrated that selecting bony injuries can be treated operatively with immediate internal fixation [9]. For the use of antibiotic, a controversy still exists [4] [12]. Howland and Ritchey [6] reported a low infection rate and no advantage in patients treated with antibiotics, and these results made them advocate against the use of antibiotics in the treatment of such injuries.

At our center, the orthopaedic and trauma surgeons tend to be more aggressive in treating civilian's extremity gunshot fracture by a standard protocol. Treatment methods before the introduction of this protocol (i.e., skeletal traction or external fixation or plaster splint) required prolonged hospital stays and/or yielded suboptimal clinical results [13]. The purpose of this paper is to present and discuss our experience in the management of civilian gunshot fractures of extremities.

\section{Materials and Methods}

\subsection{Treatment Protocol}

In January 2007, a treatment protocol was put in place for the evaluation and management of fractured extremities resulting from civilian gunshot wounds at the department of orthopaedic surgery of the SO Medical University, the reference center of our country. Physical examination includes the basic principles of advanced trauma life support.

The standard methods include: 1) cleansing and copious lavage; 2) early debridement of necrotic tissues; 3) surgical exploration and bullets removal if possible; 4) treatment of associated injuries essentially vascular; 5) immediate or delay internal fixation according to soft tissues viability; 6 ) in case of delay internal fixation, the fracture was stabilized by skeletal traction or posterior plaster splint, the patient is returned to operating room in 2 to 3 days for another debridement, internal fixation is done when all necrotic tissue has been removed and when the bone is covered with healthy soft tissue; 7) tetanus prophylaxis; 8) antibiotics, usually Ceftriaxone $2 \mathrm{~g}$, intravenous for one to three days; 9) immediate closure of operative skin incisions and delayed closure of bullets entry and exit; 10) sterile dressings which were changed every day.

The hospital ethical committee approved the study. Informed consent from the patients has been obtained.

\subsection{Patients Data}

Seventy six patients with 79 fractures had been managed by this protocol for gunshot fractures at the authors' hospital between January 2007 and January 2013. Nine patients with nine fractures were lost to follow-up. Four patients with six fractures died of his concomitant penetrating injuries before the definitive fixation of the fracture.

The final study population was composed of 63 patients with 64 fractures. There were 56 male and seven female. Their mean age was 33.1 years (range: 17 - 61 years). Thirteen patients (20.6\%) were able to provide a description of the weapon as a handgun or civilian's rifle whereas the remaining patients could not describe the weapon responsible for the injury (Table 1). Only 15 patients had entry and exit wounds.

\subsection{Evaluation}

Patients were interviewed and daily observed during their hospitalisation. Surveillance was continued if the 
Table 1. Characteristics of patients.

\begin{tabular}{|c|c|c|}
\hline Characteristics & Number & Percentage $(\%)$ \\
\hline \multicolumn{3}{|l|}{ Sex } \\
\hline Male & 56 & 88.9 \\
\hline Female & 07 & 11.1 \\
\hline \multicolumn{3}{|l|}{ Age group (years) } \\
\hline $0-19$ & 11 & 17.5 \\
\hline $20-39$ & 32 & 50.8 \\
\hline $40-59$ & 16 & 25.4 \\
\hline$>60$ & 04 & 06.3 \\
\hline \multicolumn{3}{|l|}{ Body mass index $\left(\mathrm{kg} / \mathrm{m}^{2}\right)$} \\
\hline$<18.5$ & 12 & 19.1 \\
\hline $18.5-25.0$ & 25 & 39.7 \\
\hline $25.1-30.0$ & 20 & 31.7 \\
\hline$>30.1$ & 06 & 09.5 \\
\hline \multicolumn{3}{|l|}{ Description of the weapon } \\
\hline Yes & 13 & 20.6 \\
\hline No & 50 & 79.4 \\
\hline \multicolumn{3}{|l|}{ Comorbidities present } \\
\hline Any & 42 & 66.7 \\
\hline Diabetes mellitus & 09 & 14.3 \\
\hline HIV infection & 06 & 09.5 \\
\hline HTA & 06 & 09.5 \\
\hline \multicolumn{3}{|l|}{ Associated injuries } \\
\hline Any & 44 & 69.8 \\
\hline Vascular injury & 03 & 04.8 \\
\hline Nerve damage & 08 & 12.7 \\
\hline Compartment syndrome & 05 & 07.9 \\
\hline Abdominal or chest wound & 03 & 04.8 \\
\hline \multicolumn{3}{|l|}{ Fracture sites } \\
\hline Femur & 21 & 32.8 \\
\hline Tibia & 08 & 12.5 \\
\hline Humerus & 15 & 23.4 \\
\hline Radius & 03 & 04.7 \\
\hline Ulna & 09 & 14.1 \\
\hline Metatarsus & 05 & 07.8 \\
\hline Metacarpus & 03 & 04.7 \\
\hline \multicolumn{3}{|c|}{ Fractures pattern according to AO classification } \\
\hline A & 00 & 00.0 \\
\hline B & 23 & 35.9 \\
\hline $\mathrm{C}$ & 41 & 64.1 \\
\hline \multicolumn{3}{|l|}{ Operative modalities } \\
\hline Interlocking nailing & 34 & 53.1 \\
\hline Plates and screws fixation & 11 & 17.2 \\
\hline Kirschner intramedullary nailing & 19 & 29.7 \\
\hline
\end{tabular}

patients were discharged. The patients had full access to the outpatient clinic if they had questions or any problems occurred. In the case of site infection, extra visits were made if needed.

The mean follow-up period was 27 (range: 20 - 58) months. The main factors assessed were the surgical site infection, the fracture union and the functional status.

Surgical site infection was classified as superficial (no need of another debridement procedure but only oral antibiotics were given), and deep (required at least one debridement procedure and IV and oral antibiotics were given).

Initial injury, post-reduction, and final follow-up radiographs were reviewed. The fracture was defined as clinically united when the fracture site was no longer tender. Radiographic union was defined as extension of trabeculae across the fracture, the presence of bridging callus, and obliteration of the fracture line.

Short Musculoskeletal Function Assessment (SMFA) questionnaire was completed by each patient at the latest follow-up visit. The 46-item SMFA questionnaire consists of the dysfunction index, which has 34 items for 
the assessment of patient's functional status, and the bother index, which has 12 items for the assessment of how much patients are bothered by functional problems. In the SMFA assessment system, higher scores show poorer outcome [14].

The data was analysed using SPSS Statistics version 17.0 (SPSS Inc, Chicago, IL, USA). A p-value $<0.05$ indicated statistical significance.

\section{Results}

\subsection{Wound Infection}

Out of the 63 patients treated for civilian gunshot fracture by our standard protocol, 14 patients developed a wound infection. The incidence rate was $22.2 \%$. There were five superficial and seven deep infections.

In case of presence of associated injuries (like vascular injury, nerve injury, compartment syndrome) or comminuted fracture type $\mathrm{C}$, the incidence rate of infection was respectively $68.4 \%$ and $29.3 \%$ (Table 2).

Twelve (85.7\%) of the infections were culture positive, and 11 (91.7\%) of them had polymicrobial infections. The most isolated bacteria were Staphylococcus Aureus, Staphylococcus epidermidis, Pseudomonas spp. After prolonged antibiotics and/or debridement, the infections were resolved.

Analysis showed that wound infection was significantly associated with:

1) Presence of associated injuries: in case these complications, the rate of infection was significantly different

Table 2. Demographic and surgical factors associated with surgical site infections after internal fixation for gunshot fracture.

\begin{tabular}{|c|c|c|c|}
\hline \multirow[b]{2}{*}{ Demographic/Surgical factor } & \multicolumn{2}{|c|}{ No. (\%) } & \multirow[b]{2}{*}{ p-value } \\
\hline & $\begin{array}{l}\text { With infection } \\
\qquad(n=14)\end{array}$ & $\begin{array}{l}\text { Without infection } \\
\qquad(n=49)\end{array}$ & \\
\hline $\begin{array}{c}\text { Sex } \\
\text { Male }(n=56) \\
\text { Female }(n=07)\end{array}$ & $\begin{array}{l}12(21.4) \\
02(28.6)\end{array}$ & $\begin{array}{l}44(78.6) \\
05(71.4)\end{array}$ & 0.497 \\
\hline $\begin{array}{l}\text { Age group (yrs) } \\
0-19(\mathrm{n}=11) \\
\begin{array}{c}20-39(\mathrm{n}=32) \\
40-59(\mathrm{n}=16) \\
>60(\mathrm{n}=04)\end{array}\end{array}$ & $\begin{array}{l}03(27.3) \\
07(21.9) \\
04(25.0) \\
00(00.0)\end{array}$ & $\begin{array}{l}08(72.7) \\
25(78.1) \\
12(75.0) \\
04(100.0)\end{array}$ & 0.472 \\
\hline $\begin{array}{c}\text { Body mass index }\left(\mathrm{kg} / \mathrm{m}^{2}\right) \\
<18.5(\mathrm{n}=12) \\
18.5-25.0(\mathrm{n}=25) \\
25.1-30.0(\mathrm{n}=20) \\
>30.1(\mathrm{n}=06)\end{array}$ & $\begin{array}{l}01(08.3) \\
07(28.0) \\
05(25.0) \\
01(08.3)\end{array}$ & $\begin{array}{l}11(91.7) \\
18(72.0) \\
15(75.0) \\
05(91.7)\end{array}$ & 0.499 \\
\hline $\begin{array}{l}\text { Co-morbidities present } \\
\text { Yes }(n=21) \\
\text { No }(n=42)\end{array}$ & $\begin{array}{l}04(19.0) \\
10(23.8)\end{array}$ & $\begin{array}{l}17(81.0) \\
32(76.2)\end{array}$ & 0.670 \\
\hline $\begin{array}{l}\text { Associated injuries } \\
\text { Yes }(n=19) \\
\text { No }(n=44)\end{array}$ & $\begin{array}{l}13(68.4) \\
01(02.3)\end{array}$ & $\begin{array}{l}06(31.6) \\
43(97.7)\end{array}$ & 0.0388 \\
\hline $\begin{array}{c}\text { Fracture sites } \\
\text { Femur }(\mathrm{n}=21) \\
\text { Tibia }(\mathrm{n}=08) \\
\text { Humerus }(\mathrm{n}=15) \\
\text { Radius }(\mathrm{n}=03) \\
\text { Ulna }(\mathrm{n}=09) \\
\text { Metatarsus }(\mathrm{n}=05) \\
\text { Metacarpus }(\mathrm{n}=03)\end{array}$ & $\begin{array}{l}04(19.0) \\
06(75.0) \\
00(00.0) \\
01(33.3) \\
02(22.2) \\
01(20.0) \\
00(00.0)\end{array}$ & $\begin{array}{c}17(81.0) \\
02(25.0) \\
15(100.0) \\
02(66.7) \\
07(77.8) \\
04(80.0) \\
03(100.0)\end{array}$ & 0.024 \\
\hline 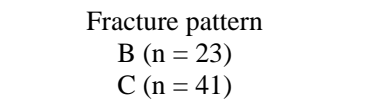 & $\begin{array}{l}02(08.7) \\
12(29.3)\end{array}$ & $\begin{array}{l}21(91.3) \\
29(70.7)\end{array}$ & 0.0412 \\
\hline $\begin{array}{c}\text { Operative modalities } \\
\text { Plates and screws }(n=11) \\
\text { Intramedullary nailing }(n=53)\end{array}$ & $\begin{array}{l}04(36.4) \\
10(18.9)\end{array}$ & $\begin{array}{l}07(63.6) \\
43(81.1)\end{array}$ & 0.0400 \\
\hline
\end{tabular}


$(\mathrm{p}=0.0388)$.

2) Fractures sites requiring fixation: the rate of infection in tibia fractures was significantly different $(\mathrm{p}=$ $0.024)$.

3) The fracture pattern: A statistically significant difference was found when the fractures were comminuted type $\mathrm{C}(\mathrm{p}=0.0412)$.

4) Operative modalities: the rate of infection between intramedullary fixation and plate and screws fixation was significantly different $(\mathrm{p}=0.0400)$.

These factors were not significantly associated with surgical site infection after internal fixation for gunshot fracture in civilians: age of patients $(\mathrm{p}=0.497)$, sex $(\mathrm{p}=0.472)$, Body mass index $(\mathrm{p}=0.499)$, and presence or absence of co-morbidities $(\mathrm{p}=0.670)$.

\subsection{Late Outcomes}

The mean follow-up period was 27 (range: 20 - 58) months. There were nine cases (14.1\%) of fracture non-union ( 1 case of femur fracture, 3 humerus, 3 tibia, 1 radius and 1 metatarsus). Bone union was achieved in 54 patients (Figure 1 and Figure 2). The mean time to union was 15 weeks (range: 5 - 32 weeks). Among them, one patients developed persistent non-union after another surgery (Figure 3). Five patients developed chronics osteomyelitis (4 tibia and 1 humerus).

The average SMFA score for all of the patients was 23.8 (range: 0 - 56.3). The mean dysfunctional and bother indexes were 18.3 (range: 0 - 52.7) and 22.6 (range: 0 - 66.1), respectively.

There was no relationship between SMFA scores and sex, age group, co-morbidities, fracture site or operatives modalities. The SMFA total score and dysfunction index had a significant correlation based on presence or absence of associated injuries $(\mathrm{p}<0.0001)$. But bother index did not show the same correlation $(\mathrm{p}=0.452)$. The mean SMFA score was 16.9 and the dysfunction index was 15.1 for the absence of associated injuries group ( $\mathrm{n}=$ 44). For the presence of associated injuries group $(n=19)$, the mean SMFA score was 23.1 and the dysfunction index was 22.4. However, bother indexes for the two groups were similar, with means of 20.7 and 21.3, respectively.

The average length of hospital stay was 11.3 days (range: 3 - 64). In case of associated injuries, the average length of hospital stay was 17.1 days (range: 10 - 64).

\section{Discussion}

Much controversy has surrounded the treatment of civilian gunshot fractures [6]-[9] [15]. In our center, treatment methods used for civilian's extremity gunshot fracture before the year 2007 were skeletal traction or external

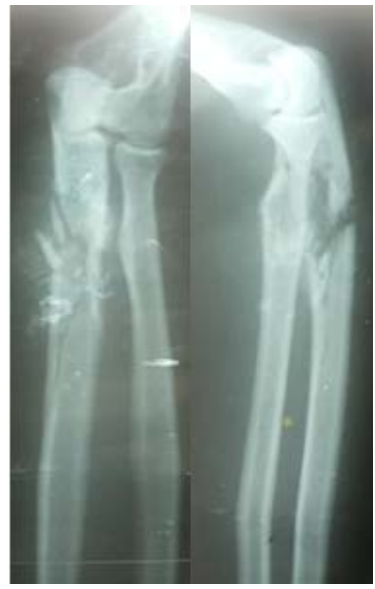

(a)

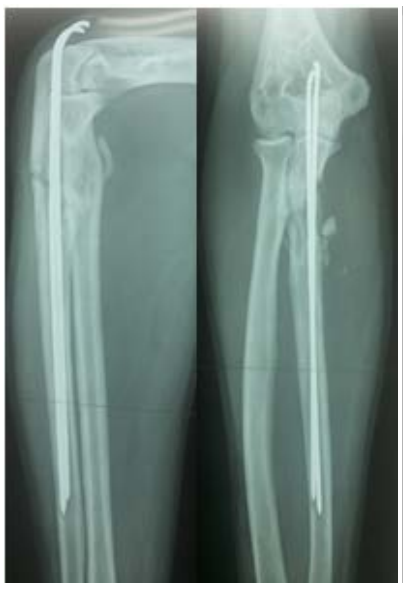

(b)

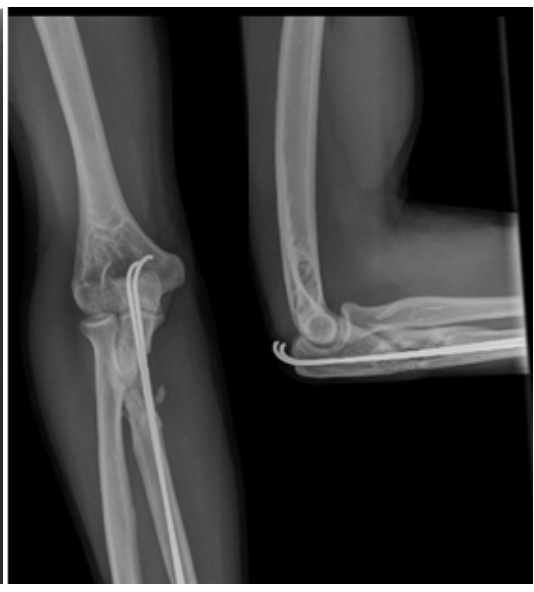

(c)

Figure 1. A 43-year-old male, civilian, sustained gunshot induced ulna fracture with associated injuries (ulna nerve palsy). (a) Anteroposterior and lateral radiographs of the fore-arm showing a comminuted ulna fracture. (b) Immediate debridement and delay (2 days) internal fixation (Kirschner intramedullary nailing). (c) Union of the fracture at eight weeks post operative. 


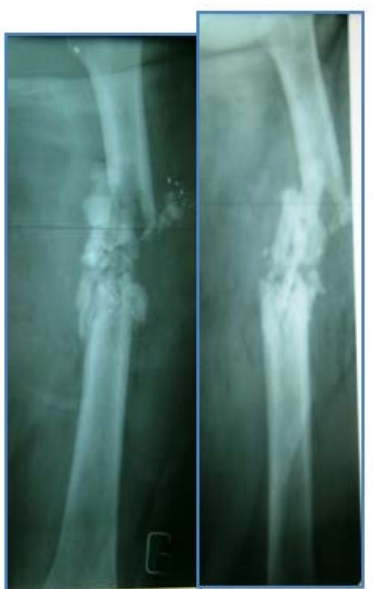

(a)

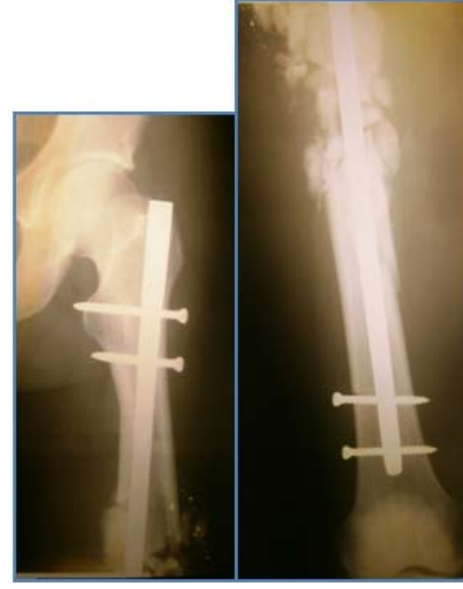

(b)

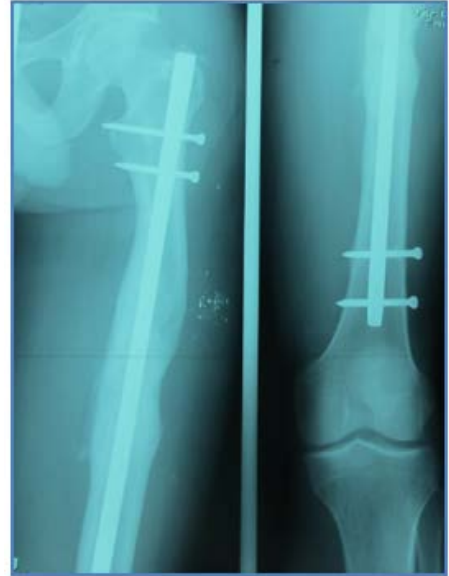

(c)

Figure 2. A 36-year-old male, civilian, sustained gunshot induced femur fracture without associated injuries. (a) Anteroposterior and lateral radiographs showing a comminuted femoral fracture. (b) Immediate debridement and internal fixation (interlocking nailing). (c) Union of the fracture at 35 weeks post operative.

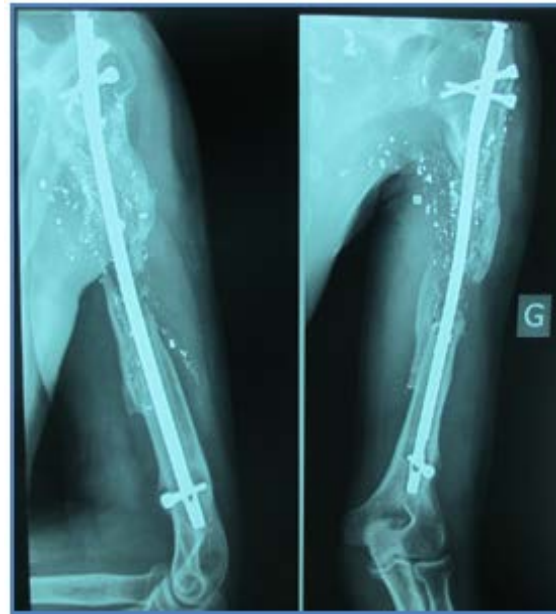

Figure 3. A 22-year-old male, civilian, sustained gunshot induced humeral fracture with associated injuries (radial nerve palsy). Immediate debridement and internal fixation (interlocking nailing). Persistent aseptic humeral pseudarthrosis after autogenous grafting and change of the nail.

fixation or conservative treatment. Some of the authors, according to the recent literature, have proposed an internal fixation after debridement. Since 2007, this protocol was used for management of civilian's gunshot fractures.

Adequate (20 to 58 months) follow-up was available to determine the rate of fracture union (85.9\%) and the incidence of wound infection (22.2\%) in the 63 patients included in the current study. Only five patients have developed a chronic osteomyelitis.

But there are some limitations of this study. Since the number of patients included in the study was relatively small, the power of the study was not great enough to estimate the effect of less frequent variables. Therefore, investigation performed on a larger number of patients would be desirable. In addition, we did not considered the number of debridement before fixation, the debridement and the qualification of the surgeon (resident, confirmed surgeon), and the number of days before internal fixation in case of delay fixation. In spite of these limitations, this study was the first longitudinal study of outcomes in internal fixation for gunshot fracture in an urban center of our country. And it was one of the few studies that accomplished a complete follow-up.

In the literature, deep and superficial infections were not separately investigated, as neither their definitions 
nor their documentation was always sufficient. Nevertheless, compared with other large published series [4] [6] [7] [12] [15] [16], we appeared to have a higher rate of wound infection. We believed that there must be some independent risk factors for developing wound infection and poor outcome after internal fixation for gunshot fracture in civilians. In the present study, two variables have been found: presence of associated injuries and comminuted fracture.

Associated injuries and the degree of comminution correlate with the arm velocity. Generally, Bullet wounds are classified as low velocity (2000 feet/second) or high velocity injuries (2000 feet/second) [17]-[20]. More importantly, however, is the amount of energy transferred from the missile to the surrounding tissues. So, the kinetic energy ( $E=1 / 2 \mathrm{MV} 2)$ of the bullet directly correlates to the wounding capacity. The higher the energy transferred to the musculoskeletal system, the greater the soft tissue disruption and fracture comminution [6]. Fortunately, most civilian handguns or rifles have relatively slow missile velocities and do not inflict cavitation and its attendant soft tissue damage [3] [6].

In our cases, we thought that some civilians' fractures were induced by higher velocity handguns or rifle. Seventy-nine percent of the patients in the current study could not describe the weapon that caused the fracture. Billings et al. [20] reviewed 44 civilians with gunshot injuries to the upper and lower extremities and found that information regarding the weapon that caused the injury was recorded only $47 \%$ of the time. A standard protocol treatment for gunshot injuries in civilians should not rely on a description of the weapon because more than $1 / 2$ of the patients cannot identify the weapon and in many cases the description is unreliable.

When the surgeon makes a decision regarding treatment with or without knowing the type of weapon, the appearance and the exploration of the wound dictates the course of treatment. So, we often taught our residents how to determine the presence or absence of muscle necrosis. Muscle is considered viable if it bleeds when cut, and the color is not pale or dusky. Contractility is tested by squeezing the muscle belly lightly with forceps or stimulating it with a cautery tip. Internal fixation can be done immediately after the wound exploration if the soft tissues are viable. But often, during the first debridement, it is difficult to distinguish living from dead muscle, especially in large wounds with extensive cavitation. In this case, a debridement of "second look" is needed. We proposed an external fixation in case of early infection. Soft tissue reconstruction with a muscle flap can be done if needed.

One major factor, not assessed in this study, was the use of antibiotic. Despite extensive experience with civilian low-velocity gunshot wounds, no consensus exists on use of antibiotics for treatment of these injuries [21]. Minor soft tissue wounds can successfully be treated in an outpatient basis, as was shown by Ordog et al. [22], who reported an infection rate of $1.8 \%$ (with associated minor fractures in only $4 \%$ ). In the presence of fractures, many investigators advocate the use of antibiotics after gunshot trauma of the extremities [7] [12] [15] [16]. Our decision to administer Ceftrixone, a long acting, broad-spectrum, third-cephalosporin, was based on a clinical trial of gram stains obtained prior to the initiation of the present protocol. The only question asked by some of us was how long antibiotics should be administered. Many patients in the protocol received three days of antibiotics, sometimes one or two according to the surgeon. No evidence was found that longer antibiotic coverage is of benefit for gunshot-induced fractures treated either nonoperatively or with fixation. This issue is not adequately addressed in the literature [21]-[24].

Our study was not a randomized controlled trial. But it has helped us to evaluate our procedure in managing civilian's gunshot fracture.

\section{Conclusion}

Assessment of penetrating trauma to the extremities has its foundation in history, physical examination, plain radiographs, and surgical wound exploration. In civilian's gunshot induced fractures, internal fixation can be made according to standard protocol, with acceptable result. Additional research is indicated to determine the proper timing of internal fixation and the duration and the optimal administration route of antibiotics.

\section{Conflict of Interest}

None.

\section{References}

[1] Russotti, G.M. and Sim, F.H. (1985) Missile Wounds of the Extremities: A Current Concepts Review. Orthopedics, 8, 
1106-1116.

[2] Max, W. and Rice, D.P. (1993) Shooting in the Dark: Estimating the Cost of Firearm Injuries. Health Affairs (Millwood), 12, 171-185. http://dx.doi.org/10.1377/hlthaff.12.4.171

[3] Brettler, D., Sedlin, E.D. and Mendes, D.G. (1979) Conservative Treatment of Low Velocity Gunshot Wounds. Clinical Orthopaedics and Related Research, No. 140, 26-31.

[4] Dickey, R.L., Barnes, B.C., Kearns, R.J. and Tullos, H.S. (1989) Efficacy of Antibiotics in Low-Velocity Gunshot Fractures. Journal of Orthopaedic Trauma, 3, 6-10. http://dx.doi.org/10.1097/00005131-198903010-00002

[5] Bartlett, C.S., Helfet, D.L., Hausman, M.R. and Strauss, E. (2000) Ballistics and Gunshot Wounds: Effects on Musculoskeletal Tissues. Journal of the American Academy of Orthopaedic Surgeons, 8, 21-36.

[6] Howland Jr., W.S. and Ritchey, S.J. (1971) Gunshot Fractures in Civilian Practice. An Evaluation of the Results of Limited Surgical Treatment. The Journal of Bone \& Joint Surgery, 53, 47-55.

[7] Woloszyn, J.T., Uitvlugt, G.M. and Castle, M.E. (1988) Management of Civilian Gunshot Fractures of the Extremities. Clinical Orthopaedics and Related Research, No. 226, 247-51.

[8] Molinari, R.W., Yang, E.C., Strauss, E. and Einhorn, T.A. (1994) Timing of Internal Fixation in Low-Velocity Extremity Gunshot Fractures. Contemporary Orthopaedics, 29, 335-339.

[9] Bergman, M., Tornetta, P., Kerina, M., Sandhu, H., Simon, G., Deysine, G. and Alcindor, F. (1993) Femur Fractures Caused by Gunshots: Treatment by Immediate Reamed Intramedullary Nailing. The Journal of Trauma, 34, 783-785. http://dx.doi.org/10.1097/00005373-199306000-00005

[10] Hollmann, M.W. and Horowitz, M. (1990) Femoral Fractures Secondary to Low Velocity Missiles: Treatment with Delayed Intramedullary Fixation. Journal of Orthopaedic Trauma, 4, 64-69. http://dx.doi.org/10.1097/00005131-199003000-00011

[11] Wiss, D.A., Brien, W.W. and Becker Jr., V. (1991) Interlocking Nailing for the Treatment of Femoral Fractures Due to Gunshot Wounds. Journal of Bone and Joint Surgery, 73, 598-606.

[12] Hansraj, K.K., Weaver, L.D., Todd, A.O., Taylor, S.M., Griffin, M.D., Dukhram, K.M., Judd, T.P. and Hansraj, M.S. (1995) Efficacy of Ceftriaxone versus Cefazolin in the Prophylactic Management of Extra-Articular Cortical Violation of Bone Due to Low-Velocity Gunshot Wounds. Orthopedic Clinics of North America, 26, 9-17.

[13] Abalo, A., Tomta, K., Walla, A., Ayouba, G. and Dossim, A. (2010) Incidence and Risk Factors for Pin Tract Infection in Extrenal Fixation for Fractures. Nigerian Journal of Orthopaedics and Trauma, 9, 17-20. http://dx.doi.org/10.4314/njotra.v9i1.54724

[14] Swiontkowski, M.F, Engelberg, R., Martin, D.P. and Angel, J. (1999) Short Musculoskeletal Function Assessment Questionnaire: Reliability, Validity and Responsiveness. Journal of Bone and Joint Surgery, 81, 1245-1260

[15] Geissler, W.B., Teasedall, R.D., Tomasin, J.D. and Hughes, J.L. (1990) Management of Low Velocity Gunshot-Induced Fractures. Journal of Orthopaedic Trauma, 4, 39-41. http://dx.doi.org/10.1097/00005131-199003000-00007

[16] Brien, W.W., Kuschner, S.H., Brien, E.W. and Wiss, D.A. (1995) The Management of Gunshot Wounds to the Femur. Orthopedic Clinics of North America, 26, 133-138.

[17] Fackler, M.L. (1988) Wound Ballistics. A Review of Common Misconceptions. JAMA, 259, 2730-2736. http://dx.doi.org/10.1001/jama.1988.03720180056033

[18] Finck, P.A. (1965) Ballistic and Forensic Pathologic Aspects of Missile Wounds. Conversion between Anglo-American and Metric-System Units. Military Medicine, 130, 545-569.

[19] Anania, W.C., Rosen, R.C. and Giuffre, A.M. (1987) Gunshot Wounds to the Lower Extremity: Principles and Treatment. The Journal of Foot Surgery, 26, 228-232.

[20] Billings, J.B., Zimmerman, M.C., Aurori, B., Parsons, J.R. and Swan, K.G. (1991) Gunshot Wounds to the Extremities. Experience of a Level I Trauma Center. Orthopedic Reviews, 20, 519-524.

[21] Papasoulis, E., Patzakis, M.J. and Zalavras, C.G. (2013) Antibiotics in the Treatment of Low-Velocity Gunshot-Induced Fractures: A Systematic Literature Review. Clinical Orthopaedics and Related Research, 471, 3937-3944. http://dx.doi.org/10.1007/s11999-013-2884-z

[22] Ordog, G.J., Wasserberger, J., Balasubramanium, S. and Shoemaker, W. (1994) Civilian Gunshot Wounds--Outpatient Management. The Journal of Trauma, 36, 106-111. http://dx.doi.org/10.1097/00005373-199401000-00017

[23] Abghari, M., Monroy, A., Schubl, S., Davidovitch, R. and Egol, K. (2015) Outcomes Following Low-Energy Civilian Gunshot Wound Trauma to the Lower Extremities: Results of a Standard Protocol at an Urban Trauma Center. Iowa Orthopaedic Journal, 35, 65-69.

[24] Burg, A., Nachum, G., Salai, M., Haviv, B., Heller, S., Velkes, S. and Dudkiewicz, I. (2009) Treating Civilian Gunshot Wounds to the Extremities in a Level 1 Trauma Center: Our Experience and Recommendations. Israel Medical Association Journal, 11, 546-551. 